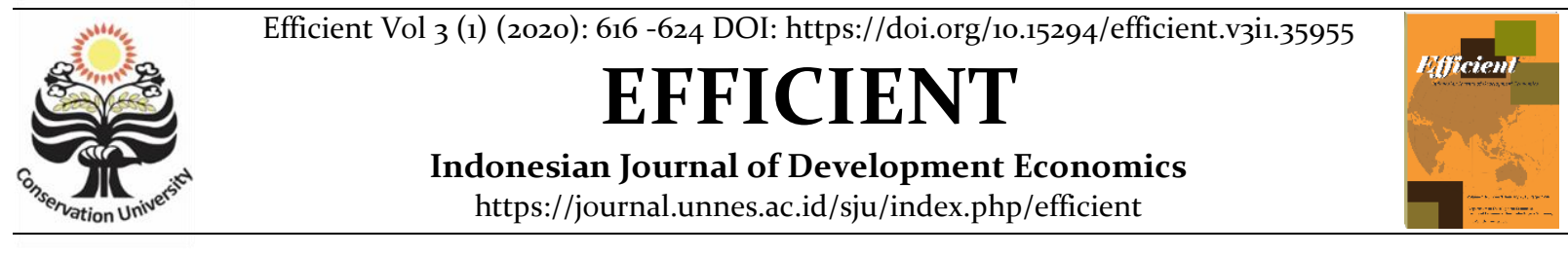

\title{
Kebijakan dan Implementasi Program Relokasi PKL Kawasan Tlogosari Kota Semarang
}

\author{
Mochammad Bisma Imanda ${ }^{1 凶}$ Rusdarti $^{2}$ \\ Jurusan Ekonomi Pembangunan, Fakultas Ekonomi, Universitas Negeri Semarang \\ Permalink/DOI: https://doi.org/10.15294/efficient.v3i1.35955 \\ Received: July 2019 ; Accepted: October 2019 ; Published: January 2020
}

\begin{abstract}
The purpose of this study is to describe the condition of street vendors in the city of Semarang Tlogosari; describe and analyze the policy of the City Government, the role of the function of the actors involved, implementation and efforts aimed at addressing the causes of the inefective of the relocation program Tlogosari street vendors in the area of Semarang. The method used is descriptive analysis with qualitative approach. The data used in the research is a secondary data. The population in this study consisted of 21 keyperson consisting of elements of Semarang City Market Agency, Chief Tlogosari Kulon village, Semarang municipal police and street vendors in the area Tlogosari. The results showed that the condition of street vendors located in the area of Semarang has Tlogosari displacement relocation traders to place, but in relocating the government does not hold a follow-up in preparing the infrastructure and facilities. The role of the function of the actors involved in the relocation of street vendors in the program Tlogosari namely the Semarang City Market Agency and the municipal police personnel Semarang. Factors that cause the inefective of the relocation program of street vendors in the city of Semarang Tlogosari them is a culture of street vendors who keep returning despite being moved, PKL reluctantly relocated to Taman Suryokusumo, and street vendors were difficult to set or disciplined. And last effort in addressing the causes of the inefective of the relocation program PKL among other actions determine the place / location for street vendors selling. City government falls directly approached PKL to speak and to deliberate.
\end{abstract}

Keywords: Policy, Implementation, PKL Relocation Program, region Tlogosari.

\begin{abstract}
Abstrak
Tujuan penelitian ini adalah untuk mendiskripsikan kondisi Pedagang Kaki Lima (PKL) di kawasan Tlogosari Kota Semarang; mendiskripsikan dan menganalisis kebijakan Pemerintah Kota, peran fungsi aktor yang terlibat, Implementasi dan upaya yang dilakukan dalam mengatasi kurang efktifnya program relokasi PKL di kawasan Tlogosari Kota Semarang. Metode penelitian yang digunakan adalah analisis deskriptif dengan pendekatan kualitatif. Data yang digunakan dalam penelitian berupa data skunder. Populasi dalam penelitian ini terdiri dari 21 keyperson yang terdiri dari unsur Dinas Pasar Kota Semarang, Kepala Kelurahan Tlogosari Kulon, Satpol PP Kota Semarang dan PKL di kawasan Tlogosari. Hasil penelitian menunjukkan bahwa Kondisi PKL yang berlokasi di kawasan Tlogosari Kota Semarang telah dilakukan pemindahan pedagang ke tempat relokasi, namun dalam melakukan relokasi pemerintah tidak mengadakan tindak lanjut dalam menyiapkan sarana dan prasarana. Peran fungsi aktor yang terlibat dalam program relokasi PKL di kawasan Tlogosari yaitu pihak Dinas Pasar Kota Semarang serta para personil Satpol PP Kota Semarang. Faktor program relokasi yang berjalan kurang baik PKL di kawasan Tlogosari Kota Semarang diantaranya adalah budaya PKL yang selalu kembali meskipun sudah dipindah, PKL enggan di relokasi ke Taman Suryokusumo, dan PKL yang sulit ditata atau ditertibkan. Dan terakhir upaya dalam mengatasi berjalan kurang baiknya program relokasi PKL antara lain melakukan tindakan menentukan tempat/lokasi berjualan bagi PKL. Pemerintah Kota terjun langsung mendekati PKL untuk berbicara dan melakukan musyawarah.
\end{abstract}

\section{Kata Kunci: Kebijakan, Implementasi, Program Relokasi PKL, Kawasan Tlogosari}

How to Cite: Imanda, M., \& Rusdarti, R. (2020). Kebijakan dan Implementasi Program Relokasi PKL Kawasan Tlogosari Kota Semarang. Efficient: Indonesian Journal of Development Economics, 3(1), 616-624. https://doi.org/10.15294/efficient.v3i1.35955

(c) 2019 Semarang State University. All rights reserved

\footnotetext{
Alamat Korespondensi :

Alamat: Gedung L2 Lantai 2 FE Unnes

Kampus Sekaran, Gunungpati, Semarang, 50229

E-mail : bismaimanda@gmail.com
}

ISSN 2655-6197 


\section{PENDAHULUAN}

Sektor informal banyak muncul di perkotaan seiring dengan pertambahan penduduk (Heriyanto, 2012). Sektor informal adalah bagian angkatan kerja kota yang berada diluar pasar tenaga terorganisasi. Sektor ini memiliki ciri tidak terorganisasi, tidak teratur, dan kebanyakan legal tetapi tidak terdaftar. Pelaku informal seperti para Pedagang Kaki Lima (PKL) merupakan suatu pelaku usaha yang memanfaatkan sarana dan prasarana umum, lahan dan bangunan milik pemerintah dan/atau swasta yang bersifat sementara ataupun menetap (Permadi,2007).

Kota Semarang merupakan ibukota Provinsi Jawa Tengah yang memiliki PKL dalam jumlah besar. Keberadaan Kota Semarang menjadi faktor penarik tersendiri bagi masyarakat untuk bekerja di sektor informal ini. Hal ini menyebabkan jumlah $\mathrm{PKL} /$ sektor informal terus bertambah setiap tahunnya. Beberapa tahun belakangan mulai marak PKL yang menggunakan mobil untuk berjualan sehingga menambah kesemrawutan wajah kota. Penyebabnya adalah pedagang bermobil tersebut parkir di sembarang tempat bahkan di lokasi yang dibilang terlarang untuk berjualan. Bertambahnya PKL dapat mengakibatkan bertambahnya permasalahan di Kota Semarang.

Tabel 1. Data PKL se-Kota Semarang

\begin{tabular}{lll}
\hline No & Tahun & Jumlah \\
\hline 1. & 2012 & 11.414 \\
2. & 2013 & 12.000 \\
3. & 2014 & 12.712 \\
4. & 2015 & 13.981 \\
\hline
\end{tabular}

Sumber : Data Statistik Dinas Pasar Kota Semarang tahun 2015
Berdasarkan tabel data PKL se-Kota Semarang di atas dapat diketahui bahwa jumlah PKL yang ada di Kota Semarang mengalami peningkatan. Semakin berkembangnya PKL yang memadati kota merupakan satu masalah yang harus segera diselesaikan oleh Pemerintah Kota Semarang. Keberadaan mereka yang tidak tertata dengan baik menimbulkan suatu kesan yang tidak baik dan juga menciptakan suatu tata kota yang buruk dan tidak nyaman. Peran nyata Pemerintah sangat dibutuhkan dalam menangani masalah PKL tersebut.

Menurut Dinas Pasar Kota Semarang PKL di kawasan Perumnas Tlogosari yang terus bertambah, dimana pada tahun 2014 hanya berjumlah 158 orang dan pada tahun 2015 meningkat menjadi 425 orang dan pada tahun 2016 meningkat menjadi 680 orang. Bertambahnya jumlah PKL mengakibatkan terhambatnya arus lalu lintas di sekitar kawasan tersebut. PKL di kawasan Tlogosari menempati badan jalan termasuk untuk pedagang bermobil sehingga menimbulkan kemacetan. Dampak negatif lain yang terjadi yakni PKL menimbulkan kekumuhan sehingga merusak keindahan kota. Kondisi ini tidak hanya terjadi di kawasan Tlogosari, namun hampir secara keseluruhan di Kota Semarang.

Pemerintah telah membuat aturan berupa SK Walikota dan Perda No. 11 Tahun 2000 tentang pengaturan dan pembinaan PKL. Dengan adanya Peraturanperaturan seharusnya program pemerintah dalam mengatur dan merelokasi dapat dijalankan dengan baik, tetapi muncul permasalahan dari PKL maupun sektor informal lainnya sehingga program relokasi banyak menemui kendala dan memngganggu proses pelaksanaan kebijakan. 
Adapun yang menjadi tujuan penelitian ini adalah untuk (1) Mendiskripsikan kondisi PKL yang berlokasi di kawasan Tlogosari Kota Semarang; (2) Mendiskripsikan dan menganalisis kebijakan Pemerintah Kota Semarang dalam program relokasi PKL di kawasan Tlogosari Kota Semarang; (3) Mendiskripsikan dan menganalisis peran dan fungsi aktor yang terlibat dalam program relokasi PKL di kawasan Tlogosari Semarang; (4) Mendiskripsikan dan menganalisis implementasi program relokasi PKL di kawasan Tlogosari Kota Semarang; (5) Mendiskripsikan dan menganalisis upaya yang dilakukan dalam mengatasi kurang efektifnya program relokasi PKL di kawasan Tlogosari Kota Semarang.

Menurut Peraturan Daerah Kota Semarang Nomor 11 Tahun 2000 dalam Pasal 1 tentang Pengaturan dan Pembinaan Pedagang Kaki Lima yang dimaksud dengan Pedagang Kaki Lima adalah pedagang yang di dalam usahanya menggunakan sarana dan perlengkapan yang mudah dibongkar pasang/dipindahkan dan atau mempergunakan tempat usaha yang menempati tanah yang dikuasai Pemerintah Daerah dan atau pihak lain.

Menurut Aji Herianto (2012) PKL adalah setiap orang yang melakukan kegiatan usaha perdagangan atau jasa, yaitu melayani kebutuhan barang-barang atau makanan yang dikonsumsi langsung oleh konsumen, yang dilakukan cenderung berpindah- pindah dengan kemampuan modal yang kecil/terbatas, dalam melakukan usaha tersebut menggunakan peralatan sederhana dan memiliki lokasi di tempat-tempat umum (terutama di atas trotoar atau sebagian badan jalan), dengan tidak mempunyai legalitas formal. Namun pengertian tentang pedagang kaki lima terus berkembang sehingga sekarang menjadi kabur artinya. Mereka tidak lagi berdagang di atas trotoar saja, tetapi disetiap jalur pejalan kaki, tempat-tempat parkir, ruang-ruang terbuka, taman-taman, terminal bahkan di perempatan jalan dan berkeliling ke rumah-rumah penduduk.

Kehadiran PKL di suatu kota pada dasarnya tidak direncanakan sehingga memunculkan permasalahan bagi suatu kota karena tidak tertata dengan rapi. Untuk mengembalikan ketertiban suatu kota muncul gagasan relokasi. Relokasi yaitu suatu upaya menempatkan kembali suatu kegiatan tertentu ke lahan yang sesuai dengan peruntukannya (Ramdhani, 2005).

\section{METODE}

Jenis dan desain penelitian yang digunakan dalam penelitian ini menggunakan metode penelitian deskriptif dengan pendekatan kualitatif. Tujuannya agar dapat mendeskripsikan data apa adanya dan menjelaskan atau menggambarkan data atau kejadian dengan kalimat-kalimat penjelasan secara kualitatif. Metode yang digunakan dalam Pengumpulan data sesuai dengan yang dilakukan oleh Aji Wahyu Herianto (2012) 
dengan menggunakan dokumentasi, kuesioner dan wawancara.

Fokus dalam penelitian ini meliputi kebijakan Pemerintah Kota Semarang dalam merelokasi PKL yang berlokasi di kawasan Tlogosari Semarang, kemudian diambil menjadi sub fokus sebagai berikut:

1. Kebijakan Pemerintah Kota Semarang dalam program relokasi PKL di kawasan Tlogosari Kota Semarang.

2. Peran dan fungsi aktor-aktor yang terlibat dalam Program relokasi PKL di kawasan Tlogosari Kota Semarang.

3. Implementasi program relokasi PKL di kawasan Tlogosari Kota Semarang diantaranya adalah budaya PKL yang selalu kembali meskipun sudah dipindah, PKL enggan di relokasi ke Taman Suryokusumo, dan PKL yang sulit ditata atau ditertibkan.

4. Solusi dalam mengatasi penyebab kurang efektifnya relokasi PKL di kawasan Tlogosari Kota Semarang.

Menurut Soegiyono (2014), sumber data yang digunakan dalam penelitian ada dua, yaitu sumber data primer dan sumber data sekunder, yaitu:

Sumber data primer adalah data yang diperoleh dari sumber pertama baik dan individu maupun perseorangan dengan penyebaran kuisioner dan hasil wawancara.

Sumber data sekunder adalah data yang diperoleh dari penelitian kepustakaan atau bahan yang bersifat teoritis yang relevan dengan penelitian buku-buku, majalah, internet dan media lainnya.

Menurut Irawan (2007), penelitian kualitatif memiliki lima fase dalam proses penelitiannya, antara lain penentuan fokus, pengembangan kerangka teori, penentuan metodologi, analisis temuan dan pengambilan kesimpulan. Lima fase tersebut tidak selalu jelas batasan-batasannya antara fase satu dan fase yang lainnya tetapi setiap fase cenderung bersifat "continuous" dan sering kali terjadi overlapping (tumpang tindih) dan pengulangan-pengulangan.

Menurut Basrowi dan Suwandi (2008), penelitian kualitatif mengutamakan analisis data secara induktif. Analisis induktif ini digunakan karena beberapa alasan. Pertama, proses induktif lebih dapat menemukan kenyataan-kenyataan ganda sebagai yang terdapat dalam data. Kedua, analisis induktif lebih dapat membuat hubungan penelitiresponden menjadi eksplisist, dapat dikenal dan akuntabel. Ketiga, analisis demikian lebih dapat menguraikan latar secara penuh dan dapat membuat keputusan-keputusan tentang dapat-tidaknya pengalihan kepada suatu latar lainnya. Keempat, analisis induktif lebih dapat menemukan pengaruh bersama yang mempertajam hubungan-hubungan. Terakhir, analisis demikian dapat memperhitungkan nilai-nilai secara eksplisit sebagai bagian dari struktur analitik. Untuk menganalisis wawancara, digunakan teknik "Conversation Analysis" seperti yang diungkapkan oleh Denzin dan Lincoln (2005). Dalam hal ini, menganalisis hasil wawancara mendalam yang telah direkam.

\section{HASIL DAN PEMBAHASAN}

\section{Deskripsi Kondisi PKL di Tlogosari Semarang}

Tlogosari merupakan kawasan yang diciptakan untuk wilayah permukiman, perdagangan serta jasa. Sehingga memungkinkan bagi para pedagang untuk menawarkan produknya kepada konsumen di 
Tlogosari karena jumlah penduduknya yang padat. Tlogosari merupakan salah satu trade mark kota Semarang, karena merupakan bagian dari salah satu tujuan bisnis terutama sebagai penyangga lingkungan bisnis di Semarang Timur.

Salah satu kegiatan bisnis yang berbasis ekonomi kerakyatan adalah dijajakannya pemenuhan kebutuhan makan, terutama makan siang dan malam dalam berbagai bentuk penawaran. Makan secara santai di pinggir sungai merupakan salah satu cara makan tradisional dengan duduk di atas kursi/dingklik dengan menggunakan meja seadanya yang dinaungi tenda aluminium sekedarnya ditambah dengan hiruk-pikuknya lalu lintas, menjadikan bantaran sungai Tlogosari Raya bagaikan pasar rakyat.

Berikut adalah jumlah PKL yang berlokasi di kawasan Tlogosari Kota Semarang sesuai dengan jenis dagangannya :

Tabel 2. Jumlah Seluruh Pedagang Kaki Lima Sesuai Jenis Dagangannya

\begin{tabular}{|c|c|c|c|}
\hline No. & Lokasi & Jenis dagangan & Jumlah \\
\hline \multirow[t]{14}{*}{1.} & Kawasan & Warung makan dan minuman (matengan dan kucingan) & 59 \\
\hline & Tlogosari & kelontong & \\
\hline & & Buah-buahan & 32 \\
\hline & & Bengkel kendaraan, & 19 \\
\hline & & Tambal ban, & 10 \\
\hline & & Konter hp dan pulsa, & 18 \\
\hline & & Warung rokok, & 7 \\
\hline & & Pakaian/konveksi, & 20 \\
\hline & & Sol sepatu, & 35 \\
\hline & & Helm & 10 \\
\hline & & Kacamata & 7 \\
\hline & & Sepatu & 10 \\
\hline & & & 13 \\
\hline & & Jumlah & 240 \\
\hline
\end{tabular}

Sumber : Dinas Pasar Kota Semarang, 2016

Dari tabel 1 di atas dapat dilihat ada 20, pedagang pakaian/konveksi ada banyaknya pedagang yang berjualan di 35, pedang jasa sol sepatu ada 10, kawasan sungai Tlogosari menurut jenis pedagang helm ada 7 , pedagang kacamata dagangannya, pedagang warung makanan ada 10, pedagang sepatu ada 13, jumlah dan minuman ada 59, pedagang kelontong pedagang yang paling banyak adalah ada 32, pedagang buah ada 19, pedagang pedagang pedagang warung makanan jasa bengkel kendaraan ada 10, pedagang dan minuman. Dan jumlah keseluruhan jasa tambal ban ada 18, pedagang jasa pedagang yang ada di ruas jalan sepanjang konter hp dan pulsa ada 7, pedagang rokok sungai kawasan Tlogosari ada 240 Orang. 
Kebijakan Pemerintah Kota Semarang dalam Program Relokasi PKL di Kawasan Tlogosari Kota Semarang

Serangkaian kegiatan dan kebijakan yang dikeluarkan oleh Pemerintah menciptakan suatu terobosan yang diwujudkan dalam langkah-langkah yang tersusun secara runtut dan terdapat dalam Perda tersebut. Langkah langkah yang dilakukan oleh Pemkot Semarang yaitu dengan pemberlakuan konsep penataan yang strategis, yaitu membuat kawasan PKL dan kantong-kantong PKL. Untuk mencapai strategi tersebut, cara-cara yang dilakukan Pemkot Semarang sebagai berikut:

1. Relokasi, kegiatan ini dilakukan bila tidak tersedia lahan di lokasi dan jumlah PKL terlalu banyak;

2. Selter Knock Down, PKL akan dibangunkan selter jika di lokasi masih tersedia lahan;

3. Tenda, dilakukan pada wilayah yang lahannya tersedia dan PKL hanya melakukan aktivitas pada malam hari;

4. Gerobak, pemberian gerobak dilakukan pada wilayah yang lahannya tidak tersedia untuk selter dan tenda. Gerobak lebih bersifat mobile, bisa dipindah-pindah setiap saat;

Penertiban, sebagai langkah terakhir jika PKL tetap membandel tidak mau mengikuti program penataan Pemkot.

Proses perwujudan rencana relokasi tersebut juga dilaksanakan melalui pendekatan sosial budaya. Pendekatan PKL melalui sosial budaya yang dilakuakan pemerintah Kota Semarang, sebagai berikut:

1. Nguwongke Uwong, mempunyai arti menempatkan manusia pada Harkat dan Martabatnya.
2. Kemitraan, mempunyai makna adanya kebersamaan dalam penataan PKL anatara masyarakat, pemerintah dan PKL itu sendiri sehingga dapat menjadi semakin dimengerti oleh pihak-pihak yang terkait.

3. Hati Nurani, Ada rasa saling mengisi antara satu pihak dengan pihak yang lain, atau PKL dengan masyarakat dan pemerintah.

4. Saling menghormati, adanya keseimbangan antar PKL, masyarakat dan pemerintah.

\section{Peran dan Fungsi Aktor yang Terlibat dalam Program Relokasi PKL di Kawasan Tlogosari Kota Semarang}

Ada 3 pihak yang kepentingannya dipengaruhi dalam kebijakan Program relokasi dan penataan PKL. Pihak-pihak tersebut yang pertama adalah pihak-pihak yang berada di lingkungan pemkot Semarang, yang memiliki tanggungjawab dalam melakukan Program relokasi dan penataan terhadap PKL. Kedua adalah masyarakat umum yang secara langsung dan tidak langsung menjadi pihak yang menerima manfaat. Dan ketiga adalah para PKL yang menjadi sasaran dalam kebijakan Program relokasi dan penataan PKL.

Pihak-pihak yang kepentingannya dipengaruhi oleh kebijakan Program relokasi dan penataan PKL dapat dilihat pada tabel 3 .

Kebijakan pengelolaan dan penataan PKL Pemerintah Kota termasuk sebagai keputusan kebijakan yang dibuat oleh pejabat pemerintah yaitu pemerintah kota Semarang yang mengesahkan atau memberi arah dan substansi kepada tindakan kebijakan publik, dengan menetapkan Perda dan menerbitkan SK walikota dan Surat Edaran Kota Semarang.

Pengesahan dan penerbitan yang kemudian diakhiri dengan penetapan Perda 
dan SK Walikota ataupun surat Edaran Kota Semarang bertujuan untuk mempermudah langkah pemerintah dalam menjalankan serangkaian kebijkan diatas. Pelaksanaan kebijakan diharapkan dapat mengatasi permasalahan yang sering timbul karena pedagang kaki lima ataupun sektor informal lainnya, sehingga dapat membawa dampak yang baik bagi masyarakat, PKL itu sendiri maupun Pemerintah Kota Semarang.

Tabel 3. Pihak yang Berkepentingan dalam Program Relokasi PKL Kawasan Tlogosari

\begin{tabular}{|c|c|c|}
\hline No & $\begin{array}{l}\text { Pihak-pihak yang } \\
\text { berkepentingan }\end{array}$ & Kepentingan \\
\hline 1 & Pemerintah & $\begin{array}{l}\text { Menciptakan kondisi jalan dan pasar yang tertib dan rapi } \\
\text { sebagai upaya menciptakan keamanan dan ketertiban kota } \\
\text { Memenuhi kepentingan dan mensejahterakan PKL }\end{array}$ \\
\hline 2 & PKL & $\begin{array}{l}\text { Adanya kepentingan untuk mencari penghasilan } \\
\text { Adanya kebutuhan ruang (tempat usaha) yang strategis untuk } \\
\text { menjangkau pembeli. }\end{array}$ \\
\hline 3. & $\begin{array}{l}\text { Masyarakat } \\
\text { umum, meliputi: } \\
\text { Pembeli } \\
\text { Pengguna jalan } \\
\text { Pedagang dan } \\
\text { pemilik } \\
\text { pertokoan }\end{array}$ & $\begin{array}{l}\text { Pembeli: } \\
\text { Kebutuhan rasa nyaman dan aman dalam aktivitas transaksi } \\
\text { (jual-beli) } \\
\text { Pengguna jalan: } \\
\text { Kebutuhan akan ruang public (trotoar, bahu jalan) yang } \\
\text { memadai } \\
\text { Kebutuhan dari adanya ketertiban dan keberaturan lalu lintas. } \\
\text { Pedagang / pemilik pertokoan: } \\
\text { Rasa kenyamanan dalam menjalankan aktivitas usaha. Sebagai } \\
\text { akibat dari adanya pembebasan teras atau lahan parkir yg } \\
\text { tertutupi oleh aktivitas PKL. }\end{array}$ \\
\hline
\end{tabular}

Sumber: data diolah di lapangan melalui wawancara.

Implementasi Program Relokasi PKL di Kawasan Tlogosari Kota Semarang Adapun faktor penyebab kurang efektifnya program relokasi PKL di kawasan Tlogosari Kota Semarang diantaranya adalah budaya PKL yang selalu kembali meskipun sudah dipindah, PKL enggan di relokasi ke Taman Suryokusumo, dan PKL yang sulit ditata atau ditertibkan. Kendala yang dihadapi oleh pemerintah dalam faktor penyebab kuranng efektifnya program relokasi PKL terjadi karena Faktor Ekonomi PKL. Banyak pedagang kaki lima yang berjualan disebabkan faktor ekonomi. Mereka terpaksa berjualan di tempat-tempat terlarang karena untuk membeli atau bahkan menyewa lahan yang resmi mereka tidak mampu, oleh karenanya mereka berjualan di tempat yang seadanya yang penting dapat memperoleh 
hasil untuk memenuhi kebutuhan hidup keluarganya.

Kendala yang dihadapi oleh pemerintah dalam faktor penyebab kurang efektifnya program relokasi PKL terjadi karena relokasi tempat jualan PKL yang tidak strategis dan memadai. Hal ini menjadikan para PKL di kawasan Tlogosari enggan di relokasi ke Taman Suryokusumo.

Kendala yang dihadapi oleh pemerintah dalam faktor penyebab kurang efektifnya program relokasi PKL berupa PKL yang sulit ditata atau ditertibkan. Hal ini karena kesadaran hukum PKL yang masih rendah.

\section{Solusi dalam Mengatasi Penyebab Kurang Efektifnya Relokasi PKL di Kawasan Tlogosari Kota Semarang}

Dari hasil penelitian yang telah penulis lakukan, maka dalam pembahasan ini dapat diketahui indikator keberhasilan implementasi kebijakan program relokasi pedagang kaki lima di Kota Semarang yang tidak memunculkan konflik adalah ketertiban, keamanan dan keindahan.

Ketertiban yang diinginkan oleh Perda No 11 Tahun 2000 melalui tindakan menunjuk dan menentukan tempat/lokasi berjualan bagi PKL berjalan sebagaimana seharusnya/ tercapai.

Suatu pandangan dan pendapat serta pemikiran PKL tentang keamanan adalah keadaan dimana tidak ada penggusuran, obrakan, "penertiban" oleh petugas. Keamanan dalam pandangan Satpol PP adalah keadaan dimana PKL patuh untuk tidak membuat keributan dan pada kenyataannya PKL tidak berjualan di tempat/lokasi yang dilarang. Keamanan dapat diwujudkan karena
Pemerintah Kota sendiri memberikan waktu yang cukup kepada para PKL untuk berbenah.

Penyeragaman, penampilan yang indah dan menarik untuk sarana PKL berjualan misalnya, gerobak, tenda dan sebagainya disetujui oleh PKL dengan syarat ada bantuan berupa dana. Sebab sebagian besar PKL adalah pengusaha golongan ekonomi lemah modal kecil dengan barang dagangan yang tidak beragam. Demikian juga jika PKL ditempatkan pada suatu lokasi tertentu yang tidak merusak keindahan taman kota atau fasilitas umum lainnya, PKL mensyaratkan bahwa tempat tersebut haruslah ramai, didatangi banyak pelanggan.

Berdasarkan dari deskripsi di atas maka tingkat ketercapaian akan ketertiban, keamanan dan keindahan dalam implementasi Perda No 11 Tahun 2000 tentang Pengaturan dan Pembinaan PKL telah dapat dilaksanakan dengan baik, namun masih berjalan kurang optimal.

\section{SIMPULAN}

Berdasarkan hasil penelitian dapat disimpulkan bahwa kondisi PKL yang berlokasi di kawasan Tlogosari Kota Semarang telah dilakukan pemindahan pedagang dari satu tempat ke tempat yang lain atau relokasi, namun PKL sendiri merasa terpaksa untuk pindah. Dalam pemindahannya PKL merasa tidak betah berdagang di Taman Suryokusumo dan kembali lagi ke kawasan Tlogosari. Kebijakan Pemerintah Kota Semarang dalam pelaksanaan relokasi PKL area sepanjang sungai kawasan Tlogosari ke Taman Suryokusumo sebagian besar sudah memenuhi aspek best practice, dengan mempertimbangkan dimensi-dimensi yang 
menjadi landasan analisis penelitian ini. Peran dan fungsi aktor-aktor yang terlibat dalam program relokasi PKL di kawasan Tlogosari Semarang dimana Walikota menjadi pembuat keputusan dan sebagai pengawas pelaksanaan program relokasi, kemudian pihak DKP dan DPU memiliki peran dan fungsi dalam pembuatan infrastruktur jalan yang ada di area sepanjang jalan kawasan sungai Tlogosari dan mengurus masalah pembongkaran dan ganti rugi yang diminta oleh PKL yang terkena relokasi, sedangkan Dinas Pengelola Pasar bertanggungjawab dalam mekanisme perelokasiannya, serta para personil Satpol PP Kota Semarang yang melakukan sosialisasi dilaksanakannya penertiban dan pemberian peringatan apabila masih tetap menempati dan berdagang di tempat yang dilarang. Implementasi program relokasi PKL di kawasan Tlogosari Kota Semarang diantaranya adalah yang berasal dari PKL sendiri yang selalu kembali meskipun sudah dipindah, PKL enggan di relokasi ke Taman Suryokusumo, dan PKL yang sulit ditata atau ditertibkan. Kemudian dari pemerintah yang kurang tegas dalam menangani para PKL yang melanggar aturan atau kebijakan yang telah ditetapkan. Kemudian permintaan masyarakat yang menginginkan tempat transaksi yang mudah dijangkau dan nyaman. Upaya yang dilakukan dalam mengatasi penyebab kurang efektifnya program relokasi PKL di kawasan Tlogosari Kota Semarang antara lain melakukan tindakan menunjuk dan menentukan tempat/lokasi berjualan bagi PKL berjalan sebagaimana seharusnya/ tercapai.

\section{DAFTAR PUSTAKA}

Basrowi \& Suwandi. (2008). Memahami Penelitian Kualitatif. Jakarta: Rineka Cipta

Denzim, Norman K., and Lincoln, Yvonna S. 2009. Handbook of qualitative research (terjemahan). Yogyakara Pustaka Pelajar.

Dinas Pasar Kota Semarang. 2012, 2013, 2014, 2015.

Irawan Soehartono. 2007. Metode Penelitian Sosial: Suatu Teknik Penelitian Bidang Ilmu Kesejahteraan. Bandung : PT. Remaja Rosdakarya

Nur Jalal, Nuh Sadik, Haselman, Syahribulan 2015. Implementing Policies Local Government Planning In The Informal Sector (Case Of Street Vendors In The Town of Merauke). INTERNATIONAL JOURNAL OF SCIENTIFIC \& TECHNOLOGY RESEARCH VOLUME 4, ISSUE 04.

Soegiyono. 2014. Metode Penelitian Kuantitatif Kualitatif Dan RED. Bandung: CV. Alfabeta.

Peraturan Daerah Kota Semarang No. 11 Tahun 2000 Tentang Pengaturan dan Pembinaan Pedagang Kaki Lima Kota Semarang

Permadi, Gilang. 2007. Pedagang Kaki Lima. Jakarta: Yudhistira

Ramdhani.2005. Ketertiban Umum dan Pedagang Kaki Lima.Yogyakarta.YPAPI.

Wahyu Herianto, Aji. 2012. Dampak Sosial Ekonomi Relokasi Pedagang Kaki Lima di Kawasan Simpang Lima dan Jalan Pahlawan Kota Semarang. EDAJ: Economics Development Analysis Journal 1 (2). 